\title{
Model for Predicting Educational Domain Rate based on the Regional Level
}

\author{
Arslan Tariq ${ }^{1}$, Iqra Tariq ${ }^{2}$, Aneela Abbas ${ }^{3}$, Muhammad Aadil Butt $^{4}$, Maimoona Shahid ${ }^{5}$, Umair Muneer Butt $^{6}$ \\ University of Lahore, Gujrat Campus, Pakistan.
}

\begin{abstract}
The geographic information system (GIS) is rapidly becoming the part of current technology trends. GIS can be used to identify the factors that become the reason for an individual to adopt a field or subject. We used GIS as a major tool with the other technologies to identify the key factors. This research has analyzed that mostly people used to migrate to other cities due to unavailability of resources in their own region. Collection of data was done with the help of Survey 123 through which we were able to collect location coordinates of participants. After that, Pilot study approach used to conduct this research. Results show that mostly user preferred to move to other cities due to unavailability of programs in local institutes. The overall idea can be used to improvement of local institutes and this research can also be used for proper and efficient allocation of facilities and resources in a region, which in turn can save money and time.
\end{abstract}

Keywords-Geographic information system; education; domain; technology; region

\section{INTRODUCTION}

The combination of GIS with online social networking have embedded GIS and location-based services into daily routine of people. This pattern not just gives the GIS people group a remarkable memorable open door for public engagement but additionally brings up some major issues about the importance and role of GIS in education. For the rapid growth of practical development of GIS [8], it is necessary that we begin a genuine exchange on what, why, and how we should instruct and prepare our understudies (and the general population) about GIS and related fields [9, 12]. Numerous have contended that the advancement of spatial knowledge must be given more unmistakable quality in training at all levels, if the up and coming age of clients of geospatial advances, including geospatially empowered online networking, is to make viable and dependable utilization of them.

With GIS and mapping technologies increasingly being used to illustrate issues ranging from earthquake relief and environmental disasters [14] to human rights abuses and the on-going war on terrorism, what extra information and abilities are required [1]? Is GIS training at last about geographic instruction [1]? Assuming this is the case, maybe GIS can take in something valuable from geographers' endeavors to connect with the general population and even conceivably to change the world in significant ways [1]. The GIS people group has a pleased record of drawing in the general population through research on open investment GIS and most as of late through volunteered geographic information (VGI) and online networking [1]. What new aggregate procedure would it be a good idea for us to create in our effort endeavors and open engagement?

GIS can be used to provide a decision-making tool for educational sectors [11] to visualize and monitor the safety, mapping buildings and infrastructure [14, 12], routing transport of campus and recruitment. Students can use GIS to be aware of the contents of different fields and disciplines they are interested in $[1,12]$. It can also provide in-demand career pathways and incorporate fieldwork. It also helps the students to explore the relationship among different geographical contents including people, climate, river systems, tree species, historical buildings, water quality, soils, landforms, natural hazards and much more. It helps students to think, understand about the world and explore content knowledge.

The geographic data can be analyzed to discover relationship across time and space [1]. GIS requires thinking critically to study the relationship among various variables including latitude, altitude, and climate and much more for example in the field of cotton production to find a suitable growing area for cotton [15]. Through GIS, spatial analysis becomes necessity for scientists, business persons and epidemiologists to solve daily problems as the world is changing rapidly by meandering rivers [13], erupting volcanoes, and human forces and shifting planets. e.g. With the help of GIS tools and applications, researchers, managers and students can think critically and scientifically to make better decisions for making differences in the changing world.

This study aims to find different resources [13, 14, 15] and fields of study by gathering data geographically. Students will be grouped according to their spatial, educational requirements through an online pool [10]. The interests of students will be critically analyzed and then will be informed with the list of related studies or localities for their future interests to pick related career pathways. This will help students to make better decisions for their future interests and careers ahead.

\section{RELATED WORK}

Geographical region based education is an old phenomenon but it is a filed in which research limited to few research articles. In $20^{\text {th }}$ century, students collected their data about their own city and village and send it to other regions of country so that people use it [2]. In 1970, the Foxfire project in Georgia urged a national movement, which aimed, was to investigating, collecting and documenting the regional based educational data across the country. The Foxfire books and magazines were highly famous and successful that time, 
students and teachers in other parts of United States used that data in their research and created the similar educational data for others $[2,3,11]$. Some students and teacher also created same type of data other than Foxfire but these never achieved the popularity of Foxfire $[3,10]$.

The region-based education do not have to be limited to research and studies. Students of Akula School (K-12) [10] have designed a website of their school which contained information related to their school and community. Heartland Community School in Henderson did the same thing [2, 3]. There are different factors that lead many young people to leave their communities [3], is unavailability of resources like higher institutes, unavailability of interested degree program, unavailability of demanded degree program according to market and such others. To overcome these factors students, want to move other regions.

\section{MATERIALS AND METHODS}

This section presents the material and methods. First of all study list of graduated students and their regional background needed to identify the geographical region-based acceptance and availability of certain filed, subject or domain. For this purpose, data was acquired through survey. Survey 123 for ArcGIS used for this purpose to collect the data from different graduated students. Survey123 for ArcGIS is an easy and intuitive form based field data collecting solution [4] that creates making, sharing, and analyzing surveys attainable in 3 easy steps: ask queries, get replies, and make improved conclusions.

Instead of being map oriented, Survey123 works with forms (or surveys), that are often used to collect data for numerous disciplines. Surveys from easy to sophisticated are authored with Survey123 and then shared in ArcGIS [4]. With the help of Survey123 mobile app, teams in the field can collect survey results with their smartphones and tablets. Surveys can also be completed and submitted in a web browser [4].

Data captured is instantly obtainable for analysis in ArcGIS to assist you and your organization make improved adoptions. Survey123 is a multipurpose data gathering solution already popular with users in public health, public works, education, disaster response, resource management and humanitarian agencies [4].

From that online survey, we identified their regional background as well as collected the information and location of their institutes in form of $\mathrm{x}$ and $\mathrm{y}$ coordinates. After collecting the data through this tool, pilot study approach used to retrieve the refined form of data. Pilot study can be defined as preliminary study that leads toward main study. It is useful to evaluate the time, cost and feasibility [5]. It is convenient for researcher to evaluate different factors in pilot study so that main study become more refine and error free. Pilot study can be defined as primarily study, which is used to investigate whether crucial components of main study are feasible or not [5]. A pilot study is a standard scientific tool for 'soft' research, permitting scientists to conduct an initial examination before committing to a full-blown experiment or study [6].

Collected data had many irrelevant information and some sort of missing information. After removing irrelevant and missed information, data shown and visualize in ArcMap after refinement. Fig 2 shown the detailed methodology for the study. Section 4 presents the results and discussion.

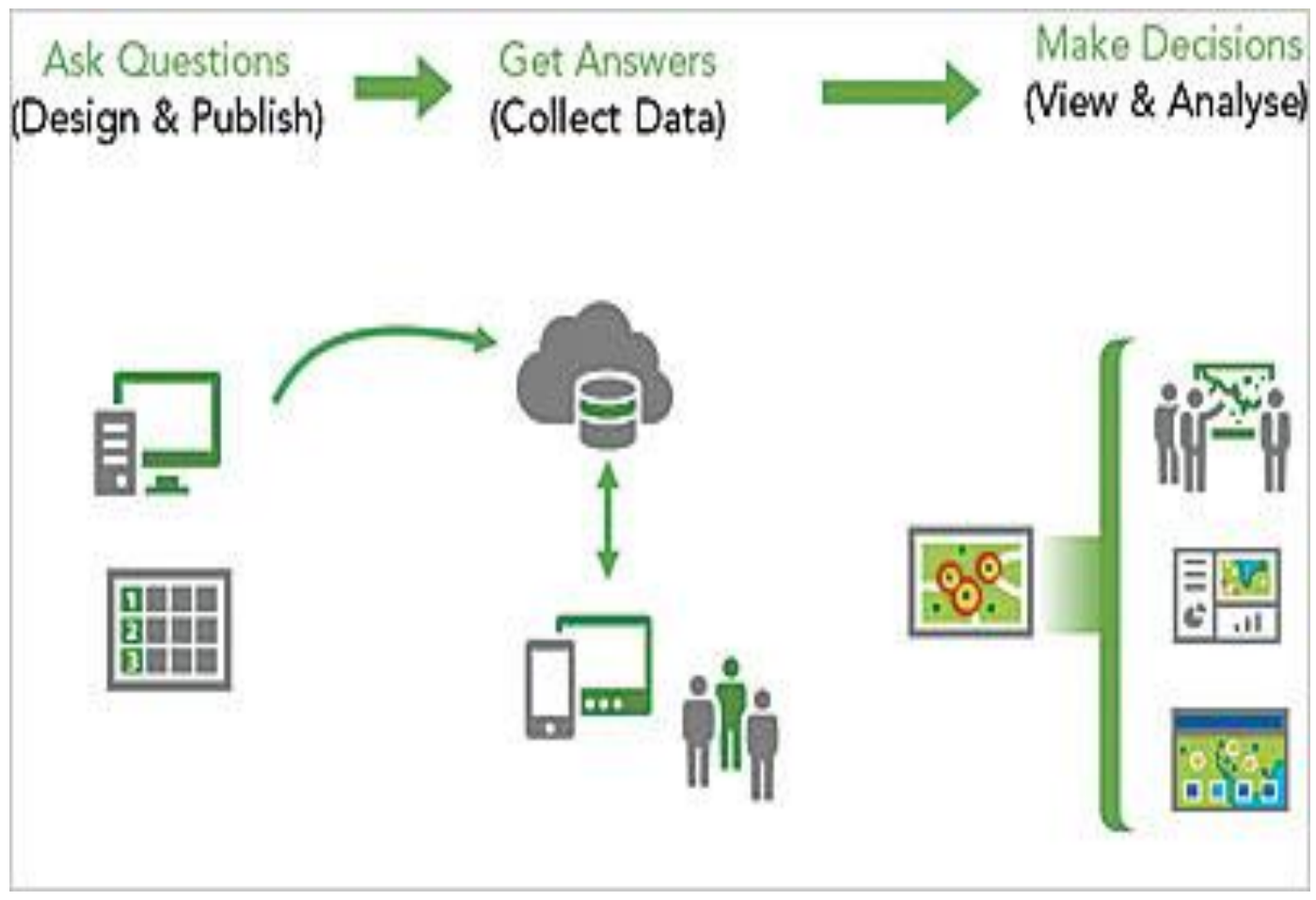

Fig. 1. 1-2-3 Simple Process for Survey 123 for ArcGIS [4]. 


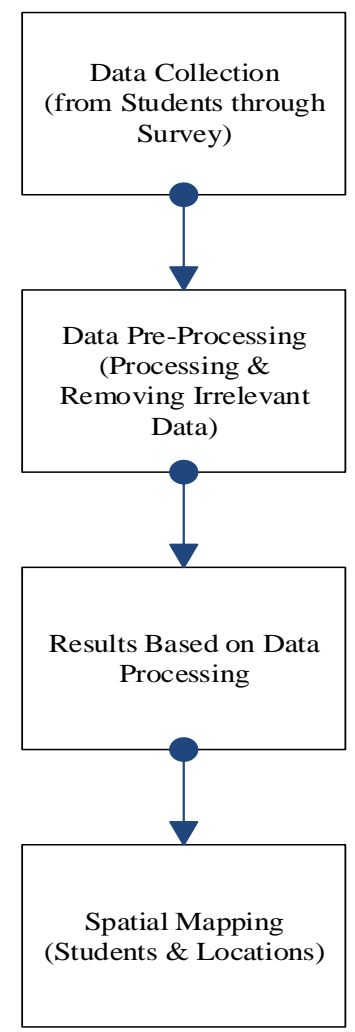

Fig. 2. Detailed Flow Chart of Methodology.

\section{RESUlts AND DisCUSSIONS}

Initially 113 users filled the online survey available online. Data of 61 users was not complete even they did not provide the information of their institutes as well as their coordinates. Some users provided wrong information related to their institutes and coordinates. It was quite difficult to identify wrong information and it was not an easy task. Shape file of Pakistan downloaded from a website [7] and refined data displayed on it in form of .csv. The shape file also have all the coordinates of data that collected through survey. Fig 3 shown the spatial mapping of collected data results.

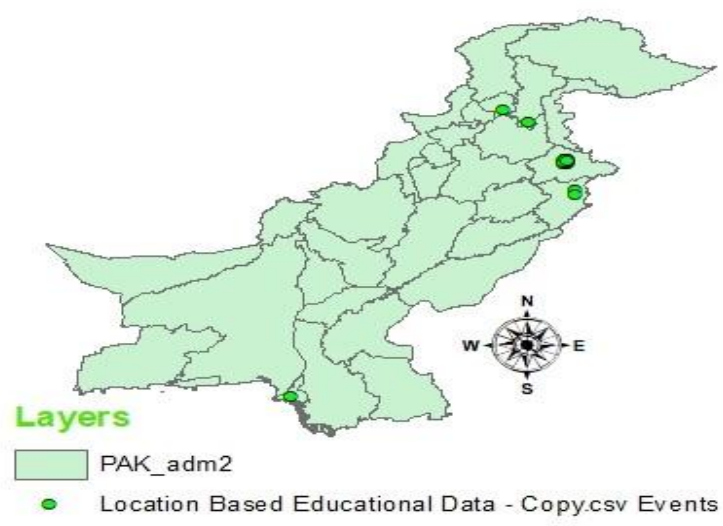

Fig. 3. Spatial Mapping of Collected Data Results.
52 participants filled the survey correctly and provided all he information correctly in all manners. 30 users participated from District Gurjat, 19 from District Gujranwala, 1 from Azad Jamu Kashmir, 1 from Karachi and 1 from Swabi. From the results of survey, we can say that 49 participants participated from Gujranwala Division. There are 21 females and 31 males and there are 7 professionals and 45 student out of 52 , filled the survey.

47 participants provided the coordinates of their institutes located in Gujranwala Division, 2 participants marked the location of their institutes in Lahore, 1 participant mark in Islamabad and remaining 2 marked their location of institutes in Mardan and Karachi respectively. Fig 4, 5, 6, 7, and 8 shown the marked location of above-mentioned results.

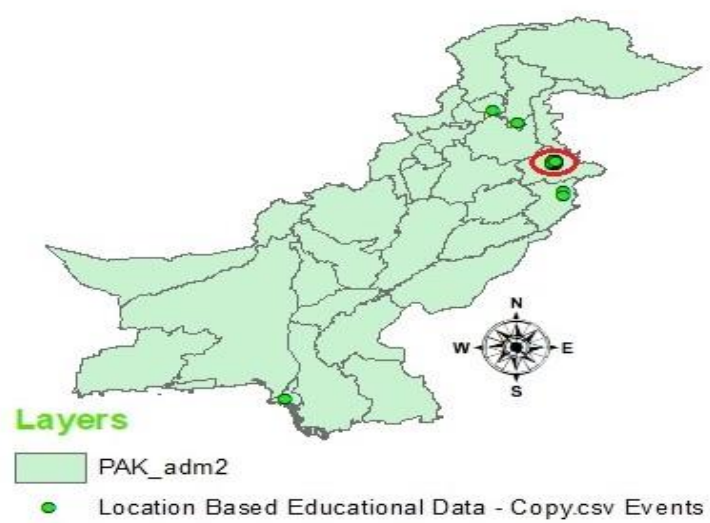

Fig. 4. Marked Location of Institutes Located in Gujranwala Division.

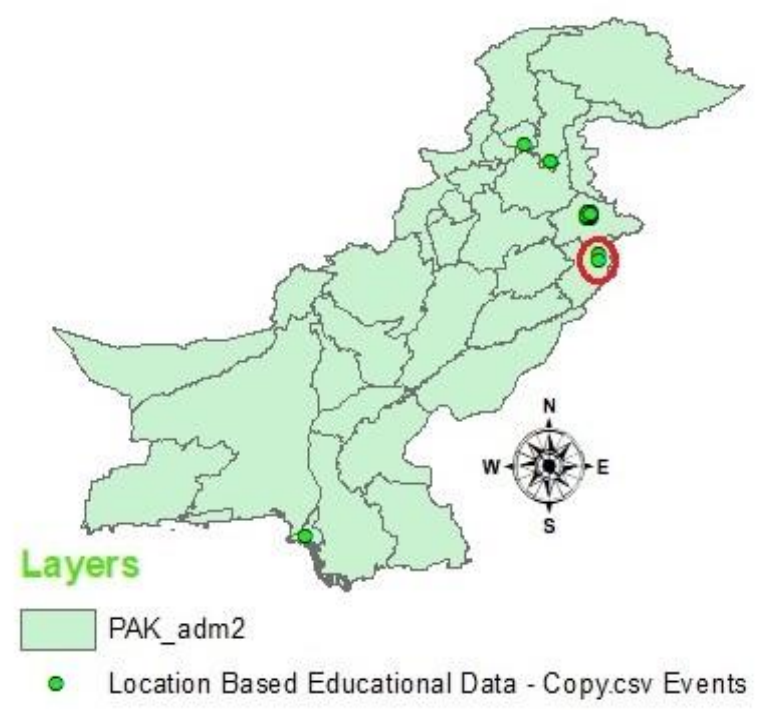

Fig. 5. Marked Location of Institutes Located in Lahore. 


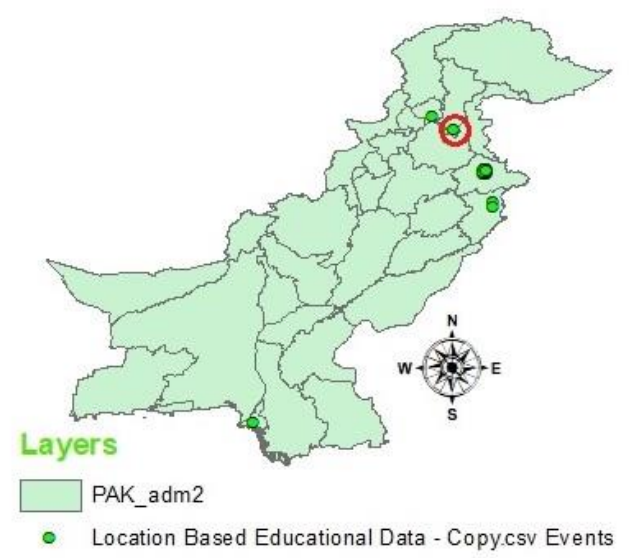

Fig. 6. Marked Location of Institutes Located in Islamabad.

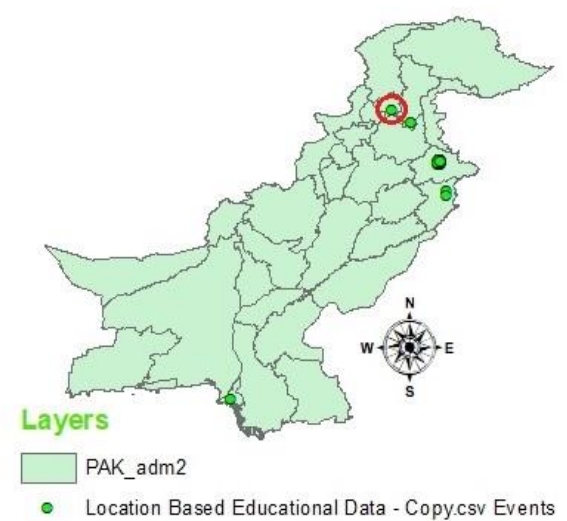

Fig. 7. Marked Location of Institutes Located in Mardan.

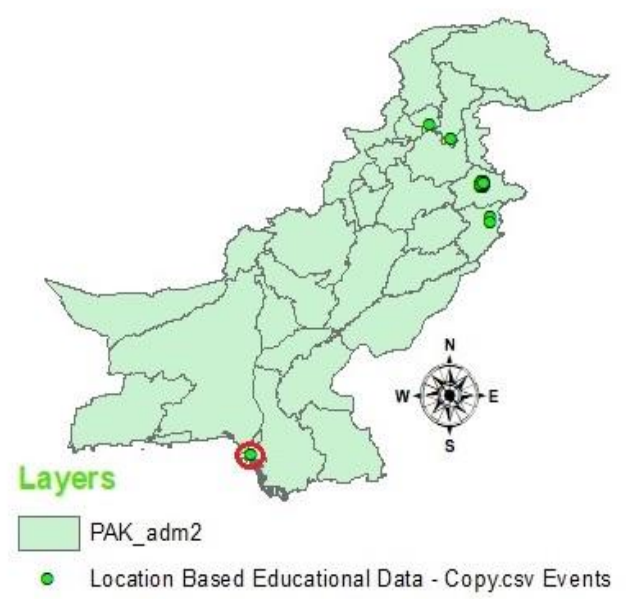

Fig. 8. Marked Location of Institutes Located in Karachi.

The qualification level of 25 participants were graduation, 18 participants had background of intermediate level and rest of 9 had the qualification level of master. Fig 9 shown the qualification level of participants.

\section{Qualification of Participants}

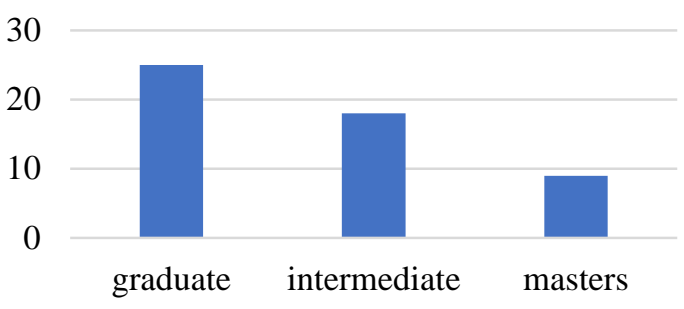

Fig. 9. Qualification Level of Participants.

The major subjects of 20 participants was computing, 15 participants belonged to medical study, 10 participants belonged to engineering study and rest 5 participants and 2 participants belonged to business and arts study respectively. Fig 10 shown the major subjects of participants.

\section{Major Subjects}

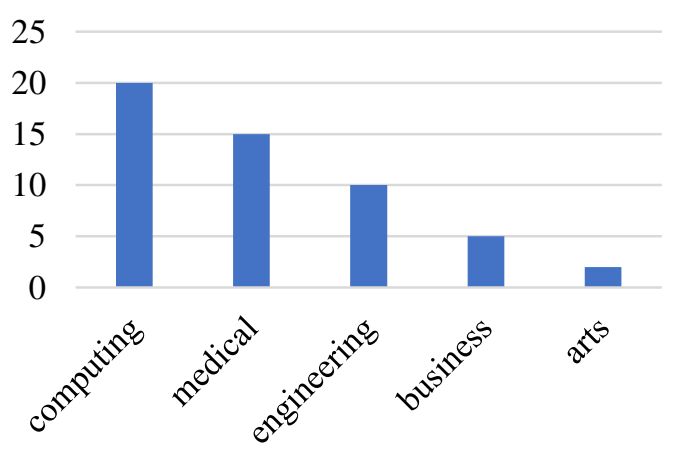

Fig. 10. Major Subjects of Participants.

The 29 participants provided the information that they were interested in the current subjects, 10 participants selected the subjects due to demand of the subjects, 8 participants selected their subjects due to influenced by someone and rest of 5 participants selected their subjects due to growth rate of that subject was increasing. Fig 11 shown the reason for selecting the field of study.

\section{Reason for Selecting Field of Study}

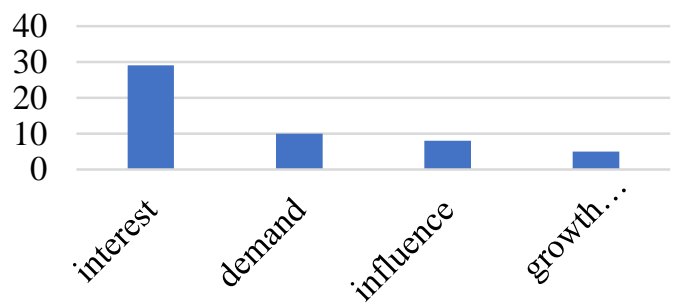

Fig. 11. Reason for Selecting of Field of Study by Participants. 


\section{Do you think field of study is influenced by area or region?}

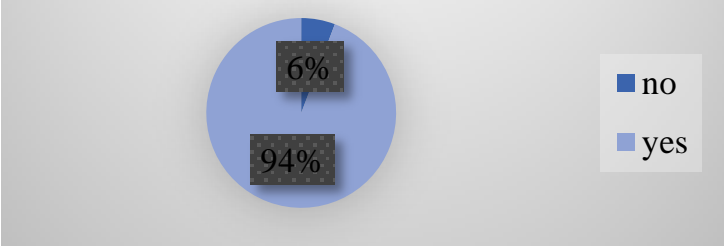

Fig. 12. Field of Study Influenced by Area or Region.

\section{Do you feel that field of study is compromised due...}

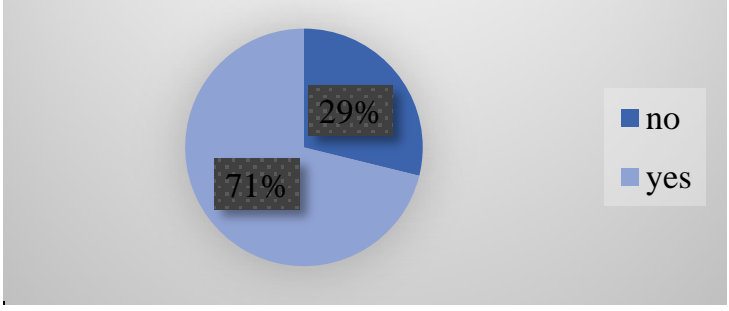

Fig. 13. Unavailability of Degree Programs in Local Institutes.

The question "Do you think field of study is influenced by area or region?" was asked in the survey. The $94 \%$ participants answered yes and only $6 \%$ answered no of that question. Fig 12 shown the percentage result of question answered by the participants.

The question "Do you feel that field of study is compromised due to unavailability of degree programs in local institutes?" was asked in the survey. The 71\% participants answered the question as yes and $29 \%$ participants answered no of that question. Fig 13 shown the percentage result of asked question by the participants.

Our research problem was to identify the geographical region-based availability and acceptance of certain domain/subjects/fields. This study guided us that there are some key factors that cause both geographical region and individual to opt or adopt any field". We have mentioned some of those key factors that have influence on individual to adopt any field regarding to their studies.

\section{CONCLUSION AND Discussions}

This study proves that the geospatial technologies can be effectively and efficiently used to identify the key factors that cause both geographical region and individual to opt or adopt a specific subject. We had used some simple and effective techniques to collect the data and after processing we were able to find the factors that effects the region based facilities and unavailability of resources. Form the survey, we analyzed that $71 \%$ participants compromised on their study due to unavailability of resources. Some of them moved to other cities and some adopted the subject due to demand, growth rate or influenced by someone. Some of them compromised due to unavailability of subject of interest in local institute and select or opt a subject that have better growth rate or demand in the market, so they join local institutes.

\section{LIMITATIONS AND FUTURE WORK}

There are few limitations associated with this study that need to be addressed and improved. We faced some difficulties during conducting of this study. The main problem was incomplete information from participants. Mostly participants did not provide all the asked information and due to missed information we decided to conducted pilot study on remain data. In future, we will conduct main study using this pilot study and will find out more constraints. We will also conduct this study based on some factors like co-education, marks in previous degree and level of satisfaction of users after adapting the subjects or filed.

\section{REFERENCES}

[1] D. Sui and M. Goodchild, "The convergence of GIS and social media: challenges for GIScience", International Journal of Geographical Information Science, vol. 25, no. 11, pp. 1737-1748, 2011.

[2] A. Murphy, "Enhancing Geography's Role in Public Debate*", Annals of the Association of American Geographers, vol. 96, no. 1, pp. 1-13, 2006.

[3] G. Smith, "Place-Based Education: Learning to Be Where We are", Phi Delta Kappan, vol. 83, no. 8, pp. 584-594, 2002.

[4] "5 Reasons to Use Survey123 for ArcGIS | ArcUser", Esri.com, 2018. [Online]. Available: http://www.esri.com/esri-news/arcuser/spring2017/5-reasons-to-use-survey123-for-arcgis. [Accessed: 01- Jun2018].

[5] "What is a pilot study? - Students 4 Best Evidence", Students 4 Best Evidence, $2018 . \quad$ [Online]. Available: https://www.students4bestevidence.net/pilot-studies/. [Accessed: 08Jun- 2018].

[6] "Pilot Study in Scientific Research - Testing a Study before Launching", Explorable.com, 2018. [Online]. Available: https://explorable.com/pilotstudy. [Accessed: 08- Jun- 2018].

[7] "Pakistan Shape files | Pakistan GIS", Pakistan GIS, 2018. [Online]. Available: http://citypulse.com.pk/pakistangis/tag/pakistan-shape-files/. [Accessed: 08- May- 2018].

[8] R. Johnston, "The point is to change it: geographies of hope and survival in an age of crisis. castree, n., chatterton, p., heynen, n., larner, w. and wright, m. w. (eds)", Geografiska Annaler: Series B, Human Geography, vol. 93, no. 4, pp. 338-340, 2011.

[9] A. Murphy, "Enhancing Geography's Role in Public Debate*", Annals of the Association of American Geographers, vol. 96, no. 1, pp. 1-13, 2006.

[10] "Learning to think spatially: GIS as a support system in K-12 education." National Academies Press, 2006.

[11] O. Darkwa and F. Mazibuko, "Creating virtual learning communities in Africa: Challenges and prospects", First Monday, vol. 5, no. 5, 2000.

[12] W. Kresse and D. Danko, Springer handbook of geographic information. Berlin: Springer, 2012.

[13] M. Clark, "Putting water in its place: a perspective on GIS in hydrology and water management", Hydrological Processes, vol. 12, no. 6, pp. 823-834, 1998.

[14] W. Craig, T. Harris and D. Weiner, Community participation and geographic information systems. New York: Taylor \& Francis, 2002, pp. 113-124.

[15] M. McCALL and P. MINANG, "Assessing participatory GIS for community-based natural resource management: claiming community forests in Cameroon", The Geographical Journal, vol. 171, no. 4, pp. 340-356, 2005. 